\title{
Sex differences in exercise induced left ventricular dysfunction in patients with syndrome $\mathrm{X}$
}

\author{
LUIGI FAVARO, $\dagger$ JOHN L CAPLIN, JURE J FETTICHE, * DUNCAN S DYMOND $\vec{\circ}$ \\ From the Departments of Cardiology and ${ }^{\star}$ Nuclear Medicine, St Bartholomew's Hospital, London
}

SUMMARY Clinical, electrocardiographic, and scintigraphic data were reviewed from 32 patients (18 men and 14 women) who had syndrome $X$ (chest pain, evidence of ischaemia, and normaliw coronary arteries without coronary vasospasm). The mean (SD) resting left ventricular ejection $\omega_{N}$ fraction, determined by first pass radionuclide angiography was $62.6(9.2) \%$ and was $>50 \%$ in allo subjects. There was no significant difference between men and women. On exercise, left ventricular ejection fraction decreased significantly to $57 \cdot 4(13.0) \%$. In 17 of 32 subjects there was a fallz in left ventricular ejection fraction of $>5 \%$, and regional wall motion abnormalities developed in 12 subjects. The fall in left ventricular ejection fraction on exercise was significant in women ${ }^{3}$ (from $61.9(8.5) \%$ at rest to $54.0(9.8) \%$ on exercise) but not in men (from $63.2(9.8) \%$ at rest to $60.0(14 \cdot 8) \%$ on exercise). Exercise left ventricular ejection fraction fell by $>5 \%$ in $10(71 \%)$ of. ${ }^{-1}$ 14 women and in seven (39\%) of 18 men. Dyskinetic segments developed in eight (57\%) of 14융 women and only four $(22 \%)$ of men. Exercise duration in women was significantly shorter than in men $(4 \cdot 1(1 \cdot 5)$ vs $6.6(2 \cdot 1)$ minutes) and was the only one of several clinical and scintigraphico variables that correlated with the change in left ventricular ejection fraction on exercise.

In this selected group of subjects with chest pain and angiographically normal coronary arteries, exercise induced left ventricular dysfunction, as shown by a fall in ejection fraction or the development of regional abnormalities, is a common finding. These are more likely to occur in women than men and are associated with a lower exercise capacity. The data suggest that the sexo of the patient is important in the interpretation of the non-invasive evaluation of subjects sus-pected of having syndrome $\mathrm{X}$.

Most of the clinical manifestations of ischaemic heart disease are due to fixed or dynamic obstruction of epicardial coronary arteries. Coronary angiography remains the gold standard by which normality or abnormality of the coronary circulation is judged and its importance in clinical decision making and prognosis cannot be denied. ${ }^{1}$

None the less, there is a subset of patients in whom there is evidence of ischaemia in the absence of abnormal coronary arteriograms or evidence of coronary vasospasm. This clinical group has been labelled as syndrome $\mathrm{X}^{2}{ }^{2}$ These patients have func-

Requests for reprints to Dr John L Caplin, Department of Cardiology, Southampton General Hospital, Tremona Road, Southampton SO9 $4 \mathrm{XY}$.

†Present address: Division of Cardiology, Ospitale di Parma, Via Gramsci, Parma, Italy.

Accepted for publication 24 November 1986 tional rather than anatomical ischaemia and are pari ticularly difficult to manage. They have been investigated by various invasive and non-invasive methods.

This study assessed the frequency of exercise in $\frac{7}{7}$ duced left ventricular dysfunction in a group of these patients and examined the differences in res sponse between male and female patients.

\section{Patients and methods}

STUDY POPULATION

The records of 174 patients were reviewed. They had been referred to the Nuclear Cardiology Labo=0 ratory in the years 1982-86 and had undergone (within one year) both coronary arteriography for $₫$ primary diagnosis of possible ischaemic heart dis $\$$ ease and exercise radionuclide angiography. One hundred and thirty five patients with obstructive $\mathrm{CO}_{\Omega}$ 
ronary artery disease (lesions of $>25 \%$ luminal diameter) were excluded, which left 39 patients with normal coronary and left ventricular angiograms. Seven further patients were subsequently excluded: two had documented myocardial infarction; two had coronary ectasia; one each had aortic stenosis, hypertrophic cardiomyopathy, and mitral valve prolapse. We studied the remaining 32 patients ( 18 men and 14 women). All had either typical anginal pain (defined as exercise or emotion induced central crushing chest pain with or without radiation to the arms or jaw), or had atypical chest pain (defined as chest pain without classic anginal features but warranting invasive cardiac investigation). No patient had a history suggestive of variant angina and none had spontaneous coronary vasospasm documented during coronary angiography. Provocation testing for coronary vasospasm was not performed in our laboratory.

\section{CORONARY ANGIOGRAPHY}

Cardiac catheterisation was performed by either the brachial or femoral artery techniques. Multiple views of each coronary artery were assessed by an experienced observer, and subjects were selected on the basis of having normal or minor irregularities (luminal narrowing $<25 \%$ ) of the coronary arteries only. All coronary arteriograms and left ventricular angiograms were reviewed and subjects with coronary ectasia, muscle bridges, coronary vasospasm, or mitral valve prolapse at the time of catheterisation were excluded.

\section{RADIONUCLIDE ANGIOGRAPHY AND EXERCISE PROTOCOL}

All antianginal medications were discontinued at least 72 hours before the study. First pass radionuclide angiography was performed with a multicrystal gamma camera (Baird Atomic System-77) as previously described. ${ }^{3}$ The patients were imaged in the upright anterior-posterior projection at rest and at then at peak exercise on an hydraulically braked bicycle ergometer (Fitron). Exercise started at a workload of $400 \mathrm{kpm} /$ minute $(66.8 \mathrm{~W})$ and increased by $200 \mathrm{kpm} /$ minute $(33.4 \mathrm{~W})$ every two minutes until a symptom limited peak was reached. A total of $950 \mathrm{MBq}(26 \mathrm{mCi})$ of technetium- $99 \mathrm{~m}$ as pertechnetate was injected for the entire study. The electrocardiogram (lead II) was monitored throughout the test, and rest and peak exercise heart rate and total exercise duration were noted.

Left ventricular ejection fraction was calculated from high frequency time-activity curves by a semiautomated method, and regional wall motion was assessed from count-based regional ejection fraction images. The left ventricular border was visually di- vided into three equal segments-inferior, apical, and anterior-and a segment was deemed to be abnormal if at least half of it had a regional ejection fraction of $<50 \%{ }^{4}$

\section{STATISTICAL ANALYSIS}

Results are expressed as mean (SD). Changes within groups were analysed by a paired $t$ test and between groups by an unpaired $t$ test, or $\chi^{2}$ tests as appropriate. Correlation coefficients $(r)$ were derived on a microcomputer with a standard software program. A p value of $<0.05$ was regarded as significant.

\section{Results}

\section{CLINICAL AND ANATOMICAL DATA}

Table 1 shows the data for the entire group and for men and women separately. There were no significant differences between men and women in age, the distribution of typical angina or atypical chest pain, abnormalities on resting or exercise electrocardiography, or the numbers of subjects with minor coronary irregularities.

The main indication for coronary angiography was typical angina in 14 patients (eight men and six women) and atypical chest pain in 18 patients (10 men and eight women). Resting electrocardiography

Table 1 Clinical and investigation data in patients with syndrome $X$

\begin{tabular}{llll}
\hline Data & Total & Men & Women \\
\hline Number & 32 & 18 & 14 \\
Mean (SD) age (years) & $48 \cdot 2(8 \cdot 8)$ & $46 \cdot 5(9 \cdot 4)$ & $50 \cdot 5(7 \cdot 9)$ \\
Typical angina (\%) & 44 & 44 & 43 \\
Atypical chest pain $(\%)$ & 56 & 56 & 57 \\
Abnormal rest ECG $(\%)$ & 19 & 11 & 29 \\
Abnormal exercise ECG (\%) & 41 & 39 & 43 \\
Minor coronary lesions (\%) & 13 & 17 & 7 \\
\hline
\end{tabular}

ECG, electrocardiogram.

Table 2 Results (mean (SD)) of the radionuclide rest and exercise studies in patients with syndrome $X$

\begin{tabular}{lccc}
\hline Variable & Total & Men & Women \\
\hline Rest HR (beats/min) & $78 \cdot 5$ & $72 \cdot 8$ & $85 \cdot 7$ \\
& $(17 \cdot 1)$ & $(12 \cdot 7)$ & $(19 \cdot 6)^{\star}$ \\
Exercise HR (beats/min) & $159 \cdot 0$ & $155 \cdot 1$ & $163 \cdot 9$ \\
& $(20 \cdot 0)$ & $(18 \cdot 8)$ & $(21 \cdot 2)$ \\
Exercise time (min) & $5 \cdot 5$ & $6 \cdot 6$ & $4 \cdot 1$ \\
& $(2 \cdot 2)$ & $(2 \cdot 1)$ & $(1 \cdot 5) \dagger$ \\
Rest EF (\%) & $62 \cdot 6$ & $63 \cdot 2$ & $61 \cdot 9$ \\
& $(9 \cdot 2)$ & $(9 \cdot 8)$ & $(8 \cdot 5)$ \\
Exercise EF (\%) & $57 \cdot 4$ & $60 \cdot 0$ & $54 \cdot 0$ \\
& $(13 \cdot 0) \ddagger$ & $(14 \cdot 8)$ & $(9 \cdot 8) \ddagger$ \\
EF $(\%)$ & $-5 \cdot 2$ & $-3 \cdot 2$ & $-7 \cdot 8$ \\
& $(10 \cdot 6)$ & $(11 \cdot 7)$ & $(8 \cdot 7)$ \\
\hline
\end{tabular}

$H R$, heart rate; EF, left ventricular ejection fraction; $\Delta$, difference between rest to exercise.

${ }^{\star} \mathrm{p}<0.05$ vs males; $\uparrow \mathrm{p}<0.01$ vs males; $\ddagger \mathrm{p}<0.01$ vs rest. 
Table 3 Number (\%) of subjects in each group with an abnormal left ventricular ejection fraction response to exercise (fall of $\geqslant 5 \%$ ), an abnormal exercise left ventricular ejection fraction $(<50 \%)$, and the development of wall motion abnormalities (see text for definitions)

\begin{tabular}{llll}
\hline Variable & Total & Men & Women \\
\hline No & 32 & 18 & 14 \\
Abnormal EF response & $17(53 \%)$ & $7(39 \%)$ & $10(71 \%)$ \\
Abnormal exercise EF & $12(37 \%)$ & $5(27 \%)$ & $7(50 \%)$ \\
Wall motion abnormality & $12(37 \%)$ & $4(22 \%)$ & $8(57 \%)$ \\
\hline
\end{tabular}

See tables 1 and 2 for abbreviations.

was abnormal in six patients: two had inferolateral ST-T segment changes, one had intermittent left bundle branch block, and three had incomplete right bundle branch block. Twenty patients $(11$ men and nine women) had treadmill exercise electrocardiographic tests; 13 (seven men and six women) were abnormal, with the development of $>1 \mathrm{~mm}$ of horizontal or downsloping ST segment depression $0.08 \mathrm{~s}$ after the J point. Four patients (three men) had minor coronary irregularities.

\section{REST AND EXERCISE RADIONUCLIDE DATA}

Table 2 shows the results derived from the radionuclide studies at rest and during exercise for all the patients, and for the groups of men and women. All patients had normal resting left ventricular ejection fraction $(>50 \%)$ and all had normal resting regional left ventricular function. On exercise, left ventricular ejection fraction fell significantly $(p<0.01)$ for the whole group; and this was almost entirely due to the fall in women $(p<0.01)$. Women also had a higher resting heart rate than men $(p<0.05)$ and a lower total exercise duration $(p<0.01)$.

Table 3 shows the frequency of abnormal left ventricular ejection fraction responses (falls of $>5 \%$ below the resting value), the number of patients with an exercise left ventricular ejection fraction below

Table 4 Clinical and radionuclide data arranged according to the response of left ventricular ejection fraction to exercise

\begin{tabular}{|c|c|c|}
\hline & \multicolumn{2}{|c|}{$\begin{array}{l}\text { Response of left ventricular ejection } \\
\text { fraction to exercise }\end{array}$} \\
\hline & Normal & $\begin{array}{l}\text { Abnormal } \\
(\text { fall } \geqslant 5 \%)\end{array}$ \\
\hline $\begin{array}{l}\text { No } \\
\text { Mean (SD) age (years) } \\
\text { Typical angina [\%] } \\
\text { Atypical chest pain [\% }[]^{\star} \\
\text { Minor coronary lesion }[\%]^{\star} \\
\text { Mean (SD) exercise time (min) } \\
\text { Mean (SD) rest EF }(\%)\end{array}$ & $\begin{array}{l}15 \\
43 \cdot 8(8 \cdot 9) \\
7[47] \\
8[53] \\
3[20] \\
6 \cdot 3(2 \cdot 4) \\
63 \cdot 9(10 \cdot 4)\end{array}$ & $\begin{array}{l}17 \\
52 \cdot 4(6 \cdot 6) \dagger \\
7[41] \\
10[59] \\
1[6] \\
4 \cdot 9(1 \cdot 9) \\
61 \cdot 5(8 \cdot 1)\end{array}$ \\
\hline
\end{tabular}

Table 5 Clinical and radionuclide data in patients with symptoms of typical angina or with atypical chest pain

\begin{tabular}{lll}
\hline & \multicolumn{2}{l}{ Chest pain } \\
\cline { 2 - 3 } Variable & Typical & Atypical \\
\hline No & 14 & 18 \\
Men $[\%]$ & $8[57]$ & $10[56]$ \\
Age (years) & $47 \cdot 0(8 \cdot 3)$ & $49 \cdot 2(9 \cdot 4)$ \\
Exercise time (min) & $5 \cdot 7(2 \cdot 0)$ & $5 \cdot 4(5 \cdot 4)$ \\
Rest EF $(\%)$ & $64 \cdot 4(10 \cdot 2)$ & $61 \cdot 3(8 \cdot 3)$ \\
Exercise EF $(\%)$ & $60 \cdot 2(14 \cdot 4)$ & $55 \cdot 2(11 \cdot 8)$ \\
$\Delta E F(\%)$ & $-4 \cdot 1(8 \cdot 1)$ & $-6 \cdot 1(12 \cdot 4)$ \\
\hline See tables 2 and 4 for abbreviations. &
\end{tabular}

See tables 2 and 4 for abbreviations.

the normal range for our laboratory $(<50 \%)$, and $y$ the frequency of regional dysfunction on exercise. $\omega$ Seventeen $(53 \%)$ of the group had an abnormal $\mathbb{N}_{N}$ global response $(71 \%$ of women and $39 \%$ of men). Half the women but only $27 \%$ of the men had an abnormal exercise left ventricular ejection fraction. Regional wall motion abnormalities developed in $12 \stackrel{2}{2}$ of the 17 patients with an abnormal global response. A total of 27 segments became abnormal in eight $(57 \%)$ women and four $(22 \%)$ men.

Of five clinical and radionuclide variables (age, resting and exercise heart rate, exercise duration, and resting ejection fraction) examined for evidence of univariate correlation with the response of the ejection fraction to exercise, only the exercise duration had any significant linear correlation $(r=\mathbb{Q}$ $0.4052, \mathrm{p}<0.05)$; but as indicated by the low $\overline{\mathrm{O}}$ coefficient this was relatively weak.

When the data were reanalysed independently of sex and according to the normality or abnormality of the response of the global ejection fraction to exercise (table 4) the only significant difference between the groups was that an abnormal response was commoner in older subjects $(p<0.01)$. There were, 3 however, no significant differences between the

Table 6 Clinical and radionuclide data in the 20 patients with either a positive or a negative exercise electrocardiogram. An abnormal EF response was a fall of $\geqslant 5 \%$ in ejection fraction from rest to exercise and an abnormal exercise $E F$ was an absolute $E F<50 \%$

\begin{tabular}{|c|c|c|}
\hline \multirow[b]{2}{*}{ Variable } & \multicolumn{2}{|c|}{ Exercise electrocardiogram } \\
\hline & Positive & Negative \\
\hline $\begin{array}{l}\text { No } \\
\text { Men }\left[{ }_{0}\right] \\
\text { Typical angina }[\%] \\
\text { Mean (SD) age (years) } \\
\text { Mean (SD) rest EF }(\%) \\
\text { Mean (SD) exercise EF }(\%) \\
\Delta E F(\%) \\
\text { Abnormal EF response }[\%] \\
\text { Abnormal exercise EF }[\%]\end{array}$ & $\begin{array}{l}13 \\
7[54] \\
6[46] \\
49 \cdot 9(7 \cdot 1) \\
63 \cdot 5(11 \cdot 0) \\
57 \cdot 3(15 \cdot 0) \\
-6 \cdot 2(9 \cdot 6) \\
8[61] \\
4[31]\end{array}$ & $\begin{array}{l}7 \\
4[57] \\
2[29] \\
51 \cdot 9(5 \cdot 6) \\
57 \cdot 8(9 \cdot 5) \\
56 \cdot 0(13 \cdot 9) \\
-1 \cdot 7(6 \cdot 0) \\
4[57] \\
3[43]\end{array}$ \\
\hline \multicolumn{3}{|c|}{ See tables 2 and 4 for abbreviations. } \\
\hline
\end{tabular}


groups with typical or atypical chest pain (table 5). Of the four patients with minimal anatomical irregularities, only one had an abnormal ejection fraction response to exercise.

Of the twenty subjects who had an exercise electrocardiogram, 13 were abnormal and seven were normal. Table 6 shows the distribution of clinical and radionuclide variables in these groups. There were no significant differences in either clinical or functional variables between subjects with a normal or abnormal exercise electrocardiogram.

\section{Discussion}

Syndrome $\mathrm{X}$, as its name implies, remains an enigma. The combination of angina and evidence of "ischaemia" on non-invasive or invasive testing, in the presence of normal or near normal coronary arteries, is one of the most difficult management problems in adult cardiology. Many methods have been used to investigate its pathophysiology, often with conflicting results.

Left ventricular end diastolic pressure has been found to decrease ${ }^{5}$ and angiographic left ventricular ejection fraction to increase ${ }^{6}$ after atrial pacing in the patients with syndrome $\mathrm{X}$ but not in patients with fixed coronary stenoses. Some investigators have been unable to induce any abnormalities of left ventricular contractility, but abnormalities in myocardial lactate production have been demonstrated in some patients, ${ }^{7}$ while others have reported significant left ventricular dysfunction after isometric exercise. ${ }^{8}$ Although "small vessel" coronary artery disease has been suggested as the condition underlying syndrome $\mathrm{X}$, Opherk $e$ t al have been unable to demonstrate any ultrastructural changes, even in subjects who showed a considerable impairment of coronary vasodilator reserve in response to dipyridamole. ${ }^{8}$ Dynamic abnormalities of the coronary microcirculation have been invoked as an explanation. ${ }^{9}$

This study has assessed the extent of exercise induced left ventricular dysfunction in a selected subset of patients with the clinical and investigational features of syndrome $X$. Left ventricular dysfunction occurred on exercise in $53 \%$ of the subjects and there was a significant fall in mean ejection fraction. Reanalysis according to sex showed that the main abnormalities in the group occurred in women $-71 \%$ had an abnormal left ventricular response to exercise. Patients with abnormal responses to exercise were significantly older than those with normal responses. These data are supported by the study of Port et al who found impairment of the "normal" left ventricular response to exercise in older subjects. ${ }^{10}$ Although the women were on aver- age older than the men in our study this difference was not statistically significant and is unlikely to be the explanation for the observed differences in left ventricular function between the sexes.

We were unable to demonstrate any differences between subjects with or without typical angina, and this contrasts with a study by Cannon et al, who demonstrated significantly lower increases in coronary flow and significantly greater increases in left ventricular end diastolic pressure after atrial pacing in syndrome $\mathrm{X}$ patients with typical angina than in those with atypical pain. ${ }^{9}$

It has been reported that up to $40 \%$ of patients with syndrome $\mathrm{X}$ have some degree of left ventricular dysfunction at rest, ${ }^{11}$ and a similar proportion have been shown to have abnormalities on exercise $^{12}$; however, this conflicts with some earlier reports where all subjects with normal coronary arteries behaved "normally". ${ }^{13}$ The variation in these results may be explained by differences in study population such as age, sex, and entry criteria. In a recent study that assessed the time course of changes in left ventricular function on exercise by rapid sequential first pass radionuclide angiography with gold $-195 \mathrm{~m}$ we found an overall increase in ejection fraction on exercise in patients with normal coronary arteries; however, all the subjects were male. ${ }^{3}$

This study has shown that patients with syndrome $\mathrm{X}$ are a non-homogeneous group and that in this group women are more likely than men to develop left ventricular dysfunction on exercise. Previous studies have also shown that falls in left ventricular ejection fraction and the development of wall motion abnormalities are associated with a reduced exercise capacity in women, ${ }^{14}$ and this is confirmed by the current data. No other previous studies have specifically examined the differences in left ventricular responses between men and women with normal coronary arteries or with syndrome $\mathrm{X}$.

The possibility remains that the observed changes in left ventricular function are a result of exercise induced coronary artery spasm. ${ }^{15}$ None of the subjects had variant angina and none had spasm during coronary arteriography. Provocation tests are not routinely performed in our laboratory, but in a study of patients with syndrome $\mathrm{X}$ challenged with ergometrine maleate there were no significant changes in luminal diameter of major coronary arteries. This was found in subjects with both typical and atypical chest pain. ${ }^{9}$ These data suggest that reactivity in large epicardial vessels is not altered in patients with syndrome $\mathrm{X}$.

A higher frequency of syndrome $\mathrm{X}$ in women was originally reported, ${ }^{5}$ although subsequently the imbalance was less in larger studies. ${ }^{9}$ The specificity of thallium-201 myocardial scintigraphy is less in 
women than in men. ${ }^{16}$ This is mainly attributed to attenuation in the breast tissue causing false positive scans, but the current findings suggest that the higher frequency may be associated with true abnormalities of global and regional left ventricular function in women with normal coronary arteriograms. Data to support this hypothesis have recently been presented by Legrand et al, who found that abnormalities in regional ventricular function on exercise in patients with syndrome $\mathrm{X}$ correlated with abnormalities of flow in the same segment. ${ }^{17}$ Thus our findings may indicate a higher frequency of true perfusion abnormalities in women.

In conclusion, we found that left ventricular dysfunction on exercise was common in patients with syndrome $\mathrm{X}$. It is more likely to occur in women and in older subjects. Because there are differences in the left ventricular response to exercise in syndrome $X$ the sex of the patient should be considered when non-invasive investigations for suspected coronary artery disease are evaluated.

\section{References}

1 The Veterans Administration Coronary Artery Bypass Surgery Cooperative Study Group. Eleven-year survival in the Veterans Administration randomized trial of coronary bypass surgery for stable angina. $N$ Engl f Med 1984;311:1333-9.

2 Opherk D, Zebe H, Weihe E, et al. Das Syndrome pektanginoser beschwerden bei Patienten mit normalen Koronarogramm (Syndrom X). Dtsch Med Wochenschr 1981;106:1686-91.

3 Caplin JL, Dymond DS, O'Keefe JC, et al. Relation between coronary anatomy and serial changes in left ventricular function on exercise: a study using first pass radionuclide angiography with gold-195m. $\mathrm{Br}$ Heart $\mathcal{F} 1986 ; 55: 120-8$.

4 Dymond DS, Foster C, Grenier RJ, Carpenter J, Schmidt DH. Peak exercise and immediate postexercise imaging for the detection of left ventricular function abnormalities in coronary artery disease. Am F Cardiol 1984;53:1532-7.

5 Arbogast R, Bourassa MG. Myocardial function during atrial pacing in patients with angina pectoris and normal coronary arteriograms. Am $f$ Cardiol 1973; 32:257-63.

6 Mammohansingh P, Parker JO. Angina pectoris with normal coronary arteriograms: hemodynamic and metabolic response to atrial pacing. Am Heart $f_{C}^{\stackrel{M}{\rightleftarrows}}$ 1975;90:555-61.

7 Boudoulas H, Cobb TC, Leighton RF, wilt CM. Myo- $\overrightarrow{\bar{s}}$ cardial lactate production in patients with angina-likechest pain and angiographically normal coronary등 arteries and left ventricle. Am $\mathcal{F}$ Cardiol 1974;34: 501-5.

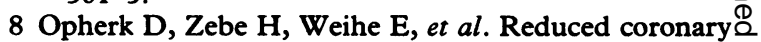
dilatory capacity and ultrastructural changes of the $\mathrm{N}_{\infty}$ myocardium in patients with angina pectoris but normal coronary arteriograms. Circulation $1981 ; \circ$ 63:817-25.

9 Cannon RO, Leon MB, Watson RM, Rosing DR, $\omega_{\omega}^{\omega}$ Epstein SE. Chest pain and "normal" coronary arteries-role of small coronary arteries. Am f G Cardiol 1985;55:50-60B.

10 Port S, Cobb FR, Coleman E, Jones RH. Effect of age $\omega$ on the response of the left ventricular ejection frac- $N$ tion to exercise. $N$ Engl f Med 1980;303:1133-7. N

11 Altieri PI, Pollack MEM, Leighton RF. Left ventricular dysfunction in patients with angina-like chest pain and angiographically normal coronary arteries 3 [Abstract]. Am ₹ Cardiol 1975;35:118.

12 Gibbons RJ, Lee KL, Cobb F, Jones RH. Ejection $\stackrel{\rho}{工}$ fraction response to exercise in patients with chest $\overrightarrow{0}$ pain and normal coronary arteriograms. Circulation $\stackrel{\infty}{\otimes}$ 1981;64:952-7.

13 Borer JS, Bacharach SL, Green MV, Kent KM, O Epstein SE, Johnston GS. Real-time radionuclide cineangiography in the non-invasive evaluation of global and regional left ventricular function at rest ${ }_{0}^{\circledR}$ and during exercise in patients with coronary-artery $\mathbb{Q}$ disease. N Engl f Med 1977;296:839-44.

14 Jones RH, McEwan P, Newman GE, et al. Accuracy of diagnosis of coronary artery disease by radionuclide measurement of left ventricular function during rest and exercise. Circulation 1981;64:586-601.

15 Caplin JL, Banim SO. Chest pain and electrocardiographic ST-segment elevation occurring in the recovery phase after exercise in a patient with normal? coronary arteries. Clin Cardiol 1985;8:228-9.

16 Okada RD. Value and limitations of myocardial scintigraphy with thallium-201 and long chain fatty acids for the detection of coronary artery disease. In: Simoons ML, Reiber JHC, eds. Nuclear imaging in 응 clinical cardiology. Boston: Martinus Nijhoff, 1984: 55-82.

17 Legrand V, Hodgson JMcB, Bates ER, et al. Abnormal coronary flow reserve and abnormal radionuclide ex- $\sigma$ ercise test results in patients with normal coronary N angiograms. $\mathcal{~} \mathrm{Am}$ Coll Cardiol 1985;6:1245-53. 